\title{
A scientific exploration of happiness: A review of the science in Exploring happiness: From Aristotle to brain science
}

\author{
Sissela Bok, Yale University Press, 2010, ISBN: 978-0-300-1329-7 (cloth), 224pp \\ Sissela Bok, Yale University Press, 2011, ISBN: 978-0-300-17810-4 (paper), 224pp
}

Review by

Matthew Aames C.

\begin{abstract}
Exploring Happiness covers the vast terrain of happiness research from Aristotle to Brain Science. But despite what the subtitle suggests, by far the greater part of the book concerns the remarks of various literary and historical figures on the concept while too few pages are reserved for the scientific findings that have surfaced in recent decades. This interesting read shines at times, most notably when it compares arm-chair theories from the distant past with modern scientific findings, but it leaves much to be desired from a perspective of scientific interest.
\end{abstract}

Keywords: happiness, satisfaction, science, measurement, psychology

\section{Introduction}

Happiness: it is what Americans report thinking about at least once a day (Lyubomirsky \& Lepper, 1999), and what they reportedly confess to valuing even more than going to Heaven (King \& Napa, 1998). Perhaps unsurprisingly then, a course on the topic attracted 855 students in one semester at Harvard, making it the most popular class at the University (Lambert, 2007). And it's not just Harvard. The hundreds of happiness courses to have sprouted up in just the last decade suggest that students all over the world are in demand of a different kind of science class: the science of happiness.

Exploring Happiness is one of a long and growing list of books released recently, aimed at meeting the high demand for enlightenment on the subject of happiness. As the title suggests, author Sissela Bok explores the vast terrain of happiness research from Aristotle to Brain Science. She does this with clarity and eloquent prose throughout. But despite what the subtitle suggests, by far the greater part of the book concerns the remarks of various literary and historical figures on the concept while too few pages are reserved for the scientific findings that have surfaced in recent decades. Even so, Exploring Happiness manages to (briefly) cover each of the major bases that social and neuro-science explores: how happy people are, what makes them happy, and what does not produce as much happiness as people tend to think. 


\section{Are people generally happy?}

One of the most intriguing aspects of Exploring Happiness is the juxtaposition between what past thinkers have theorized and what scientists have more recently found. A nice example of this is found in chapter 7 where Sigmund Freud and Bertrand Russell speculate that most people are unhappy, if not greatly so (they do disagree over whether people can become happy). Research, however, shows that most people, even in developing countries, report being happy above neutral levels. The settlement of this dispute will clearly depend on the nature of happiness itself.

\section{What is happiness?}

Exploring Happiness includes a representative array of the various happiness definitions to have been penned over the many centuries, from Aristotle's account to the more ordinary usages of today. Bok cites the definition of the economist, Richard Layard, as one of the more contemporary views of this latter kind about the nature of happiness. Layard states that happiness is "...feeling good - enjoying life and wanting the feeling to be maintained" (Layard, 2005, p. 12; quoted in Bok, p. 39).

Bok does not address concerns nor does she express opinions regarding the various proposed definitions of happiness. Thus, if one is looking for an argument which singles out the correct theory of happiness, from the recitation of what Bok considers "discordant definitions" (p. 35), one will be sorely disappointed. According to Bok, doing this is "needlessly restrictive" (p. 45). While the enterprise which Bok undertakes concerns the exploration of happiness, this raises the question: How, then, can reliable measurements be made, if what we are measuring is not uniform?

\section{Happiness measured}

According to chapter 5 on Measurement, most people think that one can be happy in multiple ways, including in the moment ("instant utility"), as well as being satisfied with one's life (or certain aspects of it). Researchers have latched on to these two definitions, which require differences in measurement. One means of measuring the latter is the Satisfaction with Life Scale.

Exploring Happiness does not relay the test-retest reliability of such surveys but Bok correctly reports that the respondents' answers are sometimes compared to their family and friends' responses about the subjects' satisfaction. Bok does not attempt to give credence to such studies nor does she report that such surveys tend to "converge with informant and spouse reports" (Van Boven, 2003, p. 1196). This omission is disappointing from the perspective of a scientific analysis of the research on happiness, as it fails to even attempt to investigate the veracity of these measures.

Bok rightly gives attention to much more recent, and significant, methods of measuring one's happiness as well: the Experience Sampling Method and the Day Reconstruction Method. Bok, however, neglects to inform the reader of the significance of the paradigm shift in the way more recent research into happiness is conducted. Prior to these research methods, which aim to capture happiness levels that people are currently experiencing (or have very recently experienced), happiness studies consisted almost exclusively of attempts to measure satisfaction levels. One important finding from these new methods is that what makes people satisfied does not always make them feel pleasure or positive affect (Kahneman \& Riis, 2005, p. 287-288). This finding may have serious implications for, among other things, some of the 
decisions we make in life (should we pursue the things that are more pleasurable or the things that make us more satisfied, when we have the choice?).

One area in which Exploring Happiness shines most is in its illumination on brain imaging studies and their uses. The shift in focus on how a person feels at any one time, rather than the satisfaction one reports, is what makes these happiness studies candidates for brain imaging research. Bok explains that scientists document the rate of blood flow, using fMRI studies, in various parts of the brain so that they can learn whether expressions of pleasure or pain stimulate particular brain areas. Research shows that positive emotions are associated with more activity in the left pre-frontal cortex. The detailing of brain imaging studies in Chapter 2, and the reporting that the left pre-frontal brain activity of Buddhist monks is far more active compared to that of non-meditators, is noteworthy. Unfortunately, it is especially noteworthy due to the fact that this is one of the only parts of Exploring Happiness that delves into the brain science of wellbeing. Bok demonstrates an understanding of some of the important work that neuro-scientists perform related to happiness measurements, but she neglects to provide her reader with more than a taste of this stimulating and groundbreaking research.

\section{Can people become lastingly happier?}

Exploring Happiness provides a compelling look into the aspects of human biology that limit the level of increased happiness one can hope to experience long term. It describes the hereditary limitations on happiness and the strong link between sources of pleasure and our adapting to those sources: a change marked by a return to our normal state. The idea that we adapt to any ups and downs in circumstances is referred to by psychologists as the hedonic treadmill. The book mentions one of the most well known pieces of evidence for the treadmill. Studies of both lottery winners and paraplegics show that they are not substantially happier or unhappier after a surprisingly short period of time than the non-wealthy and non-paralyzed, respectively. Bok balances these studies with criticisms of them, reporting that there is conflicting research as well as a charge that the studies have insufficient sample sizes.

Chapter 7 of Exploring Happiness succeeds in highlighting the fascinating findings from psychology that one has around $40 \%$ control over one's own happiness. The research states that about $50 \%$ of one's happiness is in the hands of genetics and that a meager $10 \%$ is the product of one's circumstances (wealth, material goods, etc.). The book explains that wealth tends to contribute to happiness, but the effects are often not large (e.g., many people on the Forbes list of millionaires are reportedly unsatisfied).

The $40 \%$ that is within one's control and that does not seem to succumb to adaptation (at least to any great degree) includes exercise, practicing gratitude, and work that engages one. Strong social relationships, unsurprisingly, are claimed to be the most important investment in one's happiness. Bok is careful to point out that the findings are averages and do not necessarily apply equally to everyone; and furthermore, that these positive interventions have not been tested over the long term.

\section{Conclusion}

This interesting read shines at times, such as when illuminating various theories on happiness over time and connecting the vast terrain on the topic, but it is wanting overall from a perspective of scientific interest. Exploring Happiness likely appeals most to a niche audience of those who have an interest in learning about the immense history on the subject from the perspective of mostly literary figures and who lack a need for much critical analysis. 


\section{Author}

Matthew Aames C.

University of Colorado

matthew.cucchiaro@colorado.edu

\section{References}

Kahneman, D. \& Riis, J. (2005). Living, and Thinking about it: Two Perspectives on Life. The Science of Well Being. Eds. Felicia Huppert, Nick Baylis \& Barry Keverne. Oxford University Press, Oxford, UK.

King, L. A. \& Napa, C. K. (1998). What Makes a Life Good? Journal of Personality and Social Psychology, 75, 156-165. http://dx.doi.org/10.1037/0022-3514.75.1.156

Lambert, C. (Jan.-Feb. 2007). The Science of Happiness: Psychology explores humans at their best.

Harvard Magazine. http://harvardmagazine.com/2007/01/the-science-of-happiness.html

Layard, R. (2005). Happiness: Lessons from a New Science. The Penguin Group, New York, NY.

Lyubomirsky, S. \& Lepper, H. (1999). A Measure of Subjective Happiness: Preliminary

Reliability and Construct Validation. Social Indicators Research, 46(2), 137-155.

http://dx.doi.org/10.1023/A:1006824100041

Van Boven, L. (2003). To Do or To Have? That is the question. Journal of Personality and Social Psychology, 85(6), 1193-1202. http://dx.doi.org/10.1037/0022-3514.85.6.1193 